Marquette University

e-Publications@Marquette

College of Education Faculty Research and

Publications

Education, College of

$5-2002$

\title{
Culture Counts: Examinations of Recent Applications of the Penn Resiliency Program or, Toward a Rubric for Examining Cultural Appropriateness of Prevention Programming
}

\author{
Shane J. Lopez \\ University of Kansas Main Campus \\ Lisa Edwards \\ Marquette University, lisa.edwards@marquette.edu \\ Jennifer Teramoto Pedrotti \\ University of Kansas Main Campus \\ Alicia Ito \\ University of Kansas Main Campus \\ Heather N. Rasmussen \\ University of Kansas Main Campus
}

Follow this and additional works at: https://epublications.marquette.edu/edu_fac

Part of the Education Commons

\section{Recommended Citation}

Lopez, Shane J.; Edwards, Lisa; Teramoto Pedrotti, Jennifer; Ito, Alicia; and Rasmussen, Heather N., "Culture Counts: Examinations of Recent Applications of the Penn Resiliency Program or, Toward a Rubric for Examining Cultural Appropriateness of Prevention Programming" (2002). College of Education Faculty Research and Publications. 77.

https://epublications.marquette.edu/edu_fac/77 


\title{
Culture Counts: Examinations of Recent Applications of the Penn Resiliency Program or, Toward a Rubric for Examining Cultural Appropriateness of Prevention Programming
}

\author{
Shane J. Lopez \\ University of Kansas \\ Lawrence, $K S$ \\ Lisa M. Edwards \\ University of Kansas \\ Lawrence, $K S$ \\ Jennifer Teramoto Pedrotti \\ University of Kansas \\ Lawrence, $K S$ \\ Alicia Ito \\ University of Kansas \\ Lawrence, $K S$ \\ Heather N. Rasmussen \\ University of Kansas \\ Lawrence, $K S$
}

Prevention and Treatment, Vol. 5, No. 1 (May 2002). DOI. This article is @ American Psychological Association and permission has been granted for this version to appear in e-Publications@Marquette. American Psychological Association does not grant permission for this article to be further copied/distributed or hosted elsewhere without the express permission from American Psychological Association. 
Abstract: It is imperative that researchers pay close attention to the influences of culture on mental health, and acknowledge a cultural context of illness and change when designing prevention programming. Researchers $\mathrm{E}$. V. Cardemil, K. J. Reivich, and M. E. P. Seligman (2002) and D. L. Yu and M. E. P. Seligman (2002) have made attempts at adapting the existing Penn Resiliency Program (PRP) for culturally appropriate use cross-culturally and interculturally. The success of these modifications is discussed within a framework of guidelines designed to remind scientists how much culture counts. Finally, informative resources and a rubric are shared with prevention scientists for use in future development of culturally appropriate prevention programming.

Historically, prevention scientists have done a poor job of including members of ethnic minority groups in trials of prevention programming. Furthermore, intercultural examinations of effectiveness regarding prevention strategies are seldom attempted. The complexity of cultural influences on mental health is central to developing effective services for members of our diverse U.S. population and for groups abroad. Indeed, we must acknowledge that culture counts (Department of Health and Human Services [DHHS], 2001) and address the nuances of cultural influences in our research plans, service delivery, and evaluation research.

The work of Cardemil, Reivich, and Seligman (2002) and that of Yu and Seligman (2002) demonstrates how prevention scientists can develop culturally appropriate prevention programming by testing a priori hypotheses about the role of culture in the manifestation and prevention of depression. They do so by modifying the existing Penn Resiliency Program (PRP) (to make it culturally appropriate for specific groups) and by carefully examining data to determine cultural influences on change. In this commentary we examine the extent to which the Penn research teams were successful in accounting for the role cultural factors play in mental health. In addition, we refer prevention scientists to resources designed to facilitate the development of more culturally competent intervention research. To these ends, we first summarize important guidelines provided in resources addressing cultural factors in research and practice, and we comment on how Cardemil et al. and Yu and Seligman accounted for culture in their research plans, service delivery, and manuscripts. We next refer readers to seven reports and manuscripts that guide prevention scientists in their work with diverse U.S. populations and intercultural groups. Finally we present a rubric for rating the cultural

Prevention and Treatment, Vol. 5, No. 1 (May 2002). DOI. This article is (C) American Psychological Association and permission has been granted for this version to appear in e-Publications@ Marquette. American Psychological Association does not grant permission for this article to be further copied/distributed or hosted elsewhere without the express permission from American Psychological Association. 
appropriateness of prevention research plans, service delivery, and manuscripts.

\section{Understanding the Cultural Context of the Problem}

The recent Surgeon General's Report on Mental Health: Culture, Race, \& Ethnicity (DHHS, 2001) emphasizes the importance of acknowledging that there are culture-bound syndromes, that culture influences coping strategies and social supports, and that individuals may have multiple cultural identities. Indeed, culture counts, and it is often the context of an individual's life that determines the character of his or her cultural experience.

One of the first steps in conducting culturally appropriate prevention research involves examining the cultural context of the problem or focus of prevention. Research suggests that programs that are not relevant to the cultural context of participants are likely to be ineffective (see Vera and Reese, 2000, for a discussion), but it is still common practice to implement programs without consideration of cultural values or relevance to participants. Because individuals cannot be separated from their cultural context, it is imperative to understand these cultural influences and processes before developing prevention programs. This goal of establishing culturally appropriate interventions is likely to involve communication and collaboration among researchers and all community stakeholders (including individuals who may serve as the participants in planned prevention research), and this collaboration should be considered a continuous process that informs decisions in program development as well as the delivery and evaluation of services. In fact, Reiss and Price (1996) suggest that prevention programs are most successful when members of the community support them. Again, collaboration sets the stage for members' sense of ownership. Accordingly, Lerner (1995) provides the following recommendations for putting programs into a cultural context by working collaboratively:

- Start with understanding the needs and goals of the community by including community members in the process of organizing programs.

- Develop trusting relationships between the university/agency and the community by making long-term commitments.

Prevention and Treatment, Vol. 5, No. 1 (May 2002). DOI. This article is (C) American Psychological Association and permission has been granted for this version to appear in e-Publications@Marquette. American Psychological Association does not grant permission for this article to be further copied/distributed or hosted elsewhere without the express permission from American Psychological Association. 
- Integrate issues of diversity and the sociocultural context of the community being served.

- Foster relationships between the children, parents, teachers, and community members.

Steps also should be taken to gain a thorough understanding of the cultural embeddedness of the problem or focus of prevention work. That is, the manner in which the problem is construed and explained in specific cultures should be elucidated.

\section{Examination of the PRP Applications}

Cardemil et al. (2002) and Yu and Seligman (2002) detail the two applications of PRP and describe attempts to collaborate with the communities and institutions in which the programs were implemented. While it is difficult to determine the degree of collaboration, as this is not generally a feature reported in journal articles, it is still possible to evaluate some of the efforts described. For example, Cardemil et al. discuss an application of PRP with African American and Latino children whose parents/guardians report low income. The researchers describe a rationale for working with members of these groups and highlight rates of depression and the potential benefits of a program aimed at preventing depression. Efforts to understand depression within the African American and Latino communities in which these programs were implemented are not explicitly discussed, but it is hoped that the research team sought to gain more knowledge about the problem within the context of the students' culture.

Yu and Seligman (2002) discuss three studies on depressive symptoms in Mainland Chinese children. In the first two studies, the authors examine data about depressive symptoms and explanatory style in Chinese children in an attempt to understand the cultural context of the problem. The authors describe previous studies in this area, and address social and political issues that might affect the culture and understanding of depression in children. Furthermore, Yu and Seligman discuss their use of teachers as program leaders, a practical decision that also likely increased the sense of ownership for the members of the school providing the program. Finally, the authors explicitly state that they were able to develop "good working, as well as personal, relationships with the school administration" (Yu and

Prevention and Treatment, Vol. 5, No. 1 (May 2002). DOI. This article is (C) American Psychological Association and permission has been granted for this version to appear in e-Publications@ Marquette. American Psychological Association does not grant permission for this article to be further copied/distributed or hosted elsewhere without the express permission from American Psychological Association. 
Seligman, 2002; "Strengths of This Research," paragraph 2). These relationships form the basis of effective collaboration and certainly set the stage for a better understanding of the cultural variables related to depression and its prevention.

\section{Distinguishing Between Cultures and Between Cultural Variables}

Once a cultural context is established, the prevention scientist also must be aware of many other factors that have the potential to confound results if not assessed and carefully scrutinized. Specifically, scientists must be sensitive to within-group heterogeneity, must avoid fusing race/ethnicity with socioeconomic status (SES), and must distinguish between country of origin/country of residence and culture.

\section{Within-Group Differences}

Ponterotto (1988) performed an extensive content analysis of the research focusing on racial/ethnic minority individuals that appeared in the Journal of Counseling Psychology (JCP) between the years of 1976 to 1986 . One major finding was that only $28.6 \%$ of the research designed in this period controlled for any type of within-group heterogeneity. This is a substantial problem as minority individuals often are grouped together across various racial and cultural backgrounds for the purpose of comparing them to White subjects. While others argue the validity of this type of comparison at its core (see Okazaki \& Sue, 1995, for a related discussion), the issue of the diverse make-up of the "minority" group often is overlooked. An individual of African American descent and one of Latino descent might have more in common with a Caucasian participant than they would with one another. Even if one looks at a specific race such as Asian, there are still several nationalities and cultures embedded within the group, again pointing to substantial within-group differences. Okazaki and Sue (1995) suggest making the definitions of terms such as "Asian American" or "Asian" more explicit so as to reflect within-group heterogeneity.

Cardemil et al. (2002) and Yu and Seligman (2002) attempt to address within-group differences and establish homogeneity in their sample by focusing on participants with low income and by examining Latino children separately from African American children. Several other potential differences in these samples are not discussed,

Prevention and Treatment, Vol. 5, No. 1 (May 2002). DOI. This article is (C) American Psychological Association and permission has been granted for this version to appear in e-Publications@ Marquette. American Psychological Association does not grant permission for this article to be further copied/distributed or hosted elsewhere without the express permission from American Psychological Association. 
however. For example, a statement is made as to the predominance of Puerto Rican children in the Latino sample. No specific percentages are given, however, as to the background of the other Latino participants in this study. In addition, results are discussed in terms of their meaning for Latino children from low-income backgrounds in general; it is possible that findings could be specific to Puerto Rican children. Omitting this type of descriptive data may lead journal readers to accept a myth of sameness (i.e., that all groups that are classified in a broad category are the same because of their assignment to the same category).

Secondly, and perhaps most importantly, the children in the study are grouped under the heading "minority" throughout the study. This term is not exclusive to children of Latino and African American descent and may encourage improper generalization to other populations. As recommended by Okazaki and Sue (1995), it is important to be explicit when describing participants in culturally diverse samples.

Yu and Seligman (2002) do a laudable job of examining withingroup variability in their study of depressive symptoms in Chinese children from China. These researchers examine potential differences in the levels of depressive symptoms experienced by individuals of different gender, socioeconomic status, family composition, family environment, and academic performance levels. They devote great attention to the description of their population in this area and found several significant differences between these various groups. Despite this careful approach to considering within-group differences, it is not clear if these variables are controlled during subsequent analysis of results from PRP in the third study of the article. If differences do exist, it is possible that results could be due to other factors than those hypothesized.

\section{Orthogonality of Nationality/Ethnicity and Socioeconomic Status}

Another common problem in prevention research with diverse populations is the common fusion between national/ethnic background and SES. Many researchers appear to assume that minority status communicates a lower SES. While "minority" individuals do make up a larger percentage of lower SES brackets, the linking of these two variables can be misleading. In Ponterotto's (1988) survey of the JCP

Prevention and Treatment, Vol. 5, No. 1 (May 2002). DOI. This article is (C) American Psychological Association and permission has been granted for this version to appear in e-Publications@ Marquette. American Psychological Association does not grant permission for this article to be further copied/distributed or hosted elsewhere without the express permission from American Psychological Association. 
research literature, it was found that only $30.6 \%$ emphasized the import of investigating SES in working with ethnically diverse samples. Prevention scientists must emphasize the orthogonality of nationality/ethnicity and SES variables in order to provide accurate results and conclusions.

\section{Examination of the PRP Applications}

Cardemil et al. (2002) put effort into examining socioeconomic levels in their participant pool, and then controlled for income when conducting this study. The authors subsequently make comparisons between the African American and Latino groups and describe significant differences between them in terms of income. Yu and Seligman (2002) do an excellent job of assessing the heterogeneity of their clientele in regards to socioeconomic status, determining that income levels are most likely slightly higher due to the proximity of an urban environment. The researchers discuss this potential confound in the limitations of their study, reminding readers of the limited generalizablility due to this fact.

\section{Distinctions Between Country and Culture}

The distinction between country and culture also must be addressed in prevention research. Although we often use the terms Hispanic and Hispanic American interchangeably, for example, they actually reflect two different groups of individuals. Furthermore, it is important for researchers to attend to the variability of levels of acculturation (i.e., the process that occurs from contact with members of a different cultural group [such as Caucasians] that results in socialization into an ethnic group different from one's own [Casas \& Pytluk, 1995]) in their sample to determine whether certain practices, assessments, and interventions will be appropriate for all members. Even if research participants recently have relocated to America, they are bound to vary in terms of their levels of adherence to traditional customs, beliefs, and practices. The researcher also must take into consideration the social forces that are inevitable influences upon individuals of different levels of acculturation and enculturation. Prejudice against individuals of Mexican American background may be a reality in America, whereas an individual of Mexican descent living in Mexico may not have the same experiences in regard to prejudice.

Prevention and Treatment, Vol. 5, No. 1 (May 2002). DOI. This article is (C) American Psychological Association and permission has been granted for this version to appear in e-Publications@Marquette. American Psychological Association does not grant permission for this article to be further copied/distributed or hosted elsewhere without the express permission from American Psychological Association. 


\section{Examination of the PRP Applications}

Cardemil et al. (2002) do not appear to have measured potentially differential acculturation and enculturation levels in their Latino participants. Latinos are quite culturally diverse, showing differences in terms of experiences and concerns with regards to levels of adherence to traditional Latino beliefs and values. This distinction seems especially important as a child who recently immigrated to America may experience extreme stress that could thus be correlated with the presence of depressive symptoms. Specifically, new immigrants also may be experiencing difficulties from mastery of the English language and gaining knowledge in the culture of America. In addition, children of different levels of acculturation and enculturation will most likely have a different understanding of the Western definition of depression. Because of these factors, information about country of origin, generation, and levels of acculturation and enculturation in general are extremely important components in prevention research with diverse U.S. and international samples.

In the Yu and Seligman (2002) series of studies, members of a "majority" population (Chinese children in China) are evaluated. Thus, the distinction between country and culture is not critical for this article. It is important to remind readers of this article, however, that results from this study cannot be extrapolated to Chinese or Chinese Americans in America. A Chinese individual from China, for example has not experienced the same cultural factors as a fourth-generation Chinese American, as this person (i.e., participant) is not a "minority" in China and may enjoy some status and privilege because of this fact.

\section{Developing a Culturally Appropriate Delivery System}

Culturally competent prevention research necessitates that services be adapted for different cultures. Unfortunately, there is a dearth of research on interventions targeting ethnic minority (or intercultural) populations and many of the characteristics of cultural competency in psychotherapy and counseling have been based on theory, rather than rigorous empirical study (Sue, 1998). The American Psychological Association (APA), however, offers guidelines to urge researchers and clinicians to conduct and engage in culturally appropriate research and practice. These include the Guidelines for Research in Ethnic Minority Communities (Council of National

Prevention and Treatment, Vol. 5, No. 1 (May 2002). DOI. This article is C American Psychological Association and permission has been granted for this version to appear in e-Publications@Marquette. American Psychological Association does not grant permission for this article to be further copied/distributed or hosted elsewhere without the express permission from American Psychological Association. 
Psychological Associations for the Advancement of Ethnic Minority Interests [CNPAAEMI], 2000) and the APA Guidelines for Providers of Psychological Services to Ethnic, Linguistic, and Culturally Diverse Populations (APA Office of Minority Affairs, 1992). Both of these publications assert that psychologists need to recognize that culture counts. In addition, the CNPAAEMI Guidelines highlight that psychology has been based upon Western, Eurocentric perspectives and assumptions, which in turn guide the manner in which research and delivery of services are conducted. Thus, it is important to recognize the biases and assumptions that could compromise the cultural appropriateness of services to diverse populations. Finally, both sets of guidelines emphasize the need to conduct, interpret, and disseminate research findings in a manner that is meaningful and relevant to the population under study.

Other authors have attempted to address culture, race, and ethnicity as these variables relate to the delivery of culturally competent services. For example, Sue (1998) identified three critical skill sets that prevention researchers must master. (We have taken some liberties here as we have extrapolated these recommendations from those made to therapists engaging in treatment with diverse populations.) We hope that the first recommendation is a given.

- Being scientifically minded. A researcher who is scientifically minded acknowledges that many mistakes happen because theories or assumptions that are developed in one culture are applied to clients in a different culture. Thus, a culturally competent therapist or researcher will engage in testing hypotheses about those with whom they work, rather than making quick judgments.

- Dynamic sizing. Dynamic sizing requires one to avoid stereotyping of members of a group, while still appreciating the importance of culture. It compels the psychologist to place the individual in a context, without overgeneralizing or ignoring the effects of culture.

- Understanding culture-specific elements. Culturally appropriate delivery of services requires that the helping professionals have knowledge and understanding of their own worldviews and have

Prevention and Treatment, Vol. 5, No. 1 (May 2002). DOI. This article is (C) American Psychological Association and permission has been granted for this version to appear in e-Publications@Marquette. American Psychological Association does not grant permission for this article to be further copied/distributed or hosted elsewhere without the express permission from American Psychological Association. 
specific knowledge of the target cultural group(s). The professional also needs to understand the sociopolitical influences of the target group and possess specific skills related to these.

Lerner (1995) also recommended that the existing strengths of groups be emphasized and that both environment-centered and personcentered treatment strategies be employed.

\section{Examination of the PRP Applications}

Cardemil et al. (2002) should be commended for their inclusion and awareness of culture-specific elements. They recognize that the cognitive-behavioral assumptions of PRP may not play the same role in low-income urban environments and take care not to impose middleclass, suburban values on the participants. They also modified the characters used as examples in the program to reflect the racial/ethnic diversity of the participants. Finally, they attempt to include a range of issues that are more salient to the children in the program and delivered the program during school hours to ensure a high level of attendance.

Similarly, modifications were made to the program conducted in Beijing in order to make it culturally appropriate (Yu \& Seligman, 2002). First, researchers modified the stories to include characters familiar to Chinese children. The authors took into account that restraint and social harmony are valued in Chinese culture, thus they de-emphasized the elements in the program that were contrary to these values. Also, schoolteachers were selected to be the program leaders and that helped ensure minimal disruption of the program, as harmony, order, and respect for teachers are important cultural elements.

\section{Facilitating Culturally Sensitive Evaluation}

Although the field of psychology has begun to address the influence of culture on assessment, the amount of practical information and the number of usable tests that exist are woefully inadequate. Until knowledge catches up with need, prevention scientists, program developers, and service providers are individually responsible for making culturally appropriate modifications to their 
instruments. Also, as Lerner (1995) points out, professionals evaluating programs should incorporate multiple evaluation methods.

\section{Initial Evaluation Considerations}

When evaluating research with multicultural populations, close attention must be given to the assessment instruments and procedures. A selected instrument should relate to the culturally defined research construct and must be normed and validated with the population of interest. Researchers should review the publisher's data on the inventory's normative group(s) to determine if the group tested is similar to the target population in age, gender, educational level, ethnicity, race, and linguistic ability. If the groups are dissimilar a more appropriate measure should be used (Prediger, 1994). However, due to a general lack of diversity in normative samples, it may be necessary to choose the best available measure, make culturally appropriate changes and adaptations, then revalidate the measure for the population of interest.

\section{Examination of the PRP Applications}

Although it is clear that Cardemil et al. (2002) selected instruments that are generally reliable and valid, critical information about the appropriateness of their use with racially and ethnically diverse populations is lacking. It is important that all 21st century prevention scientists consider and discuss the cultural applicability of measures so that potentially inappropriate use of instruments is not perpetuated. Yu and Seligman (2002) used measures without proven effectiveness with Mainland Chinese students, but this decision was made after the researchers discovered that useful native measures did not exist (and the rationale for this decision was described in the article).

\section{Language Considerations}

In working with diverse groups, it is imperative that participants be provided with a linguistically appropriate measure. As with most issues of culture, language considerations exist on many levels. Measure revision may range from making a few minor changes for dialectical considerations (e.g., replacing regional expressions) to complete cultural adaptation of the measure.

Prevention and Treatment, Vol. 5, No. 1 (May 2002). DOI. This article is (C) American Psychological Association and permission has been granted for this version to appear in e-Publications@Marquette. American Psychological Association does not grant permission for this article to be further copied/distributed or hosted elsewhere without the express permission from American Psychological Association. 
It is important to make the distinction between translation, which is changing the text of the test from one language to another, and adaptation, which changes material so that it assesses the construct as it is expressed in the test-takers' culture. While all adaptations will not require translation, all translations should be culturally adapted. According to Geisinger (1994), "the adaptation of assessment instruments for new target populations is generally required when the new target population differs appreciably from the original population with which the assessment device is used in terms of culture or cultural background, country, and language" (p. 304). When making changes to a measure it is important to strive for an emic perspective. To do this, researchers should not make changes in isolation; rather, they should collaborate with the stakeholders in that community to ensure cultural applicability of the measure.

Using English-language assessments with persons with nonEnglish linguistic backgrounds may be problematic because of the possible confound that exists between culture, language, and thought (Duran, 1989). To eliminate variation due to language confusion, participants with a non-English linguistic background should be given a language proficiency measure prior to any testing to determine language dominance and the appropriateness of administering the English-language version of a particular test.

\section{Examination of the PRP Applications}

Although they made cultural adaptations to the PRP program, one disappointment in the Cardemil (2002) study was the apparent lack of consideration for the possible effects of English language proficiency on the evaluation process. Yu and Seligman (2002), however, are to be commended for carefully translating and back translating the measures used in their study, making culturally appropriate adaptations, and using a pilot group to help evaluate all changes.

\section{More on Measurement Equivalence}

When valid instrumentation is not available for a particular group, as is the case for both the Cardemil et al. (2002) and Yu and Seligman (2002) projects, follow up analysis of instrument applicability is necessary. Ben-Porath (1990) recommends analyzing the equivalence of the measure across groups by first examining the

Prevention and Treatment, Vol. 5, No. 1 (May 2002). DOI. This article is (C) American Psychological Association and permission has been granted for this version to appear in e-Publications@ Marquette. American Psychological Association does not grant permission for this article to be further copied/distributed or hosted elsewhere without the express permission from American Psychological Association. 
distribution of items across groups to detect outliers and possible range restrictions. To establish cross-cultural validity, Ben-Porath recommends the use of replicatory factor analysis (i.e., using the same method that was employed in the analysis of the original measure). When instruments are adapted for use with populations that are different from the instrument's normative group, it may be inappropriate to compare results to the norms provided by the publisher without empirical validation of the metric equivalence (Okazaki \& Sue, 1995). On this topic of measurement equivalence, Knight and Hill (1998) highlight significant advances in methodologies used to establish equivalence that improve on those mentioned here. In addition Roosa, Dumka, Gonzales, and Knight (2002) also emphasized that scientists should conduct the "evaluation of measurement equivalence...in the context of the testing of theories that are informed by an understanding of the cultures in which the measures will be used" (p. 12).

\section{Disseminating Prevention Research Findings to All Stakeholders}

Collaborating with community stakeholders is considered a central element of culturally appropriate prevention research. Along with the rights afforded to scientists by community leaders come many responsibilities - the most important of which involves disseminating preliminary and final research findings to community members (especially to those individuals who participated in the research). Preliminary findings and explanations of results should be shared with the community so that alternative explanations for findings could be considered. Even if scientists have done a stellar job of collaborating with the community members to conduct a culturally appropriate intervention, nuances of the psychology of a particular culture may not be identified until community members are queried about the "fit" of the data. Research participants' and other community members' reactions should be carefully considered and appropriate modifications to the discussions of the findings should be made. In fact, we urge prevention scientists who are examining how culture counts in their findings to detail the reactions of the community members so that a culturally-grounded rationale for findings could be documented in the published manuscript (this could presented in an appendix or the

Prevention and Treatment, Vol. 5, No. 1 (May 2002). DOI. This article is (C) American Psychological Association and permission has been granted for this version to appear in e-Publications@Marquette. American Psychological Association does not grant permission for this article to be further copied/distributed or hosted elsewhere without the express permission from American Psychological Association. 
NOT THE PUBLISHED VERSION; this is the author's final, peer-reviewed manuscript. The published version may be accessed by following the link in the citation at the bottom of the page.

community members' reactions could be interwoven into the discussion).

\section{Examination of the PRP Applications}

It is assumed that in the spirit of an ongoing collaboration with the community stakeholders, the Penn prevention scientists shared their interesting findings with the research participants, PRP group leaders, and other members of the community. As the groups' reactions to the findings are not documented we cannot comment on how the community stakeholders viewed the findings and what recommendations they had for embedding the results in a richer cultural context. Fortunately, the online publication of Prevention \& Treatment allows for the publication of an addendum to the articles that might address the children's reactions to the results and the implications and the community members' level of acceptance of and explanations for the findings. Checking in with the stakeholders also may generate some valuable feedback regarding modification of PRP for particular groups. Therefore, we strongly encourage the scientists to share their findings with all stakeholders and to document the feedback.

\section{Resources for the Culturally Competent Prevention Scientist}

It was our intent to summarize the valuable guidelines for conducting culturally appropriate prevention science provided in the many resources on this topic. We hope that our work serves as a primer for those psychologists committed to becoming culturally competent prevention scientists and that this commentary provides a lens through which other prevention science involving culturally diverse samples can be evaluated. This article, though, cannot do justice to the detailed information provided in the original documents that we consulted when writing this piece. We list them here for your ease of reference: Surgeon General's Report on Mental Health: Culture, Race, \& Ethnicity (DHHS, 2001); Guidelines for Research in Ethnic Minority Communities (Council of National Psychological Associations for the Advancement of Ethnic Minority Interests, 2000); APA Guidelines for Providers of Psychological Services to Ethnic, Linguistic, and Culturally Diverse Populations (APA, 1993); Cultural/Ethnic Issues and the Prevention Scientist in the 21 st Century

Prevention and Treatment, Vol. 5, No. 1 (May 2002). DOI. This article is (C) American Psychological Association and permission has been granted for this version to appear in e-Publications@ Marquette. American Psychological Association does not grant permission for this article to be further copied/distributed or hosted elsewhere without the express permission from American Psychological Association. 
NOT THE PUBLISHED VERSION; this is the author's final, peer-reviewed manuscript. The published version may be accessed by following the link in the citation at the bottom of the page.

(Roosa et al., in press); In Search of Cultural Competence in Psychotherapy and Counseling (Sue, 1998); Cross-Cultural Normative Assessment: Translation and Adaptation Issues Influencing the Normative Interpretation of Assessment Instruments (Geisinger, 1994); Measurement Equivalence in Research Involving Minority Adolescents (Knight \& Hill, 1998).

\section{A Rubric for Examining Cultural Appropriateness of Prevention Programming}

In our first meeting to discuss our reactions to the PRP articles, we decided that we would pick the best available rubric outlining critical elements of culturally appropriate prevention practices and research to serve as a guide for evaluating the Penn researchers' work. To our surprise, we found no rubric or other forms of evaluation criteria to use for our desired purposes. Hence, we proceeded to aggregate reports and articles bearing on the topic and distilled relevant suggestions into the five guidelines offered in the body of this paper.

These guidelines were reframed as the criteria for evaluating the cultural appropriateness of prevention programming and incorporated into a basic rubric (see Table 1). We intend for this rubric to serve as one means of evaluating prevention science research plans that deal with the role of culture in illness and change. In our work, we use it as a rubric is meant to be used-as a touchstone that we return to frequently to guarantee that we are doing quality research. We hope others find it equally valuable and expand it to incorporate other qualities of culturally sound prevention science.

\section{Conclusions}

Cardemil et al. (2002) and Yu and Seligman (2002) make major strides in adapting PRP for use cross-culturally and interculturally. Their articles provide excellent examples of how to offer programs to communities (in the United States and abroad) in need. Our efforts to highlight strengths and limitations in design, service delivery, and dissemination stem from our desire to clarify how good prevention science could become exemplars of culturally appropriate science if researchers were to attend to how much culture counts.

Prevention and Treatment, Vol. 5, No. 1 (May 2002). DOI. This article is (C) American Psychological Association and permission has been granted for this version to appear in e-Publications@Marquette. American Psychological Association does not grant permission for this article to be further copied/distributed or hosted elsewhere without the express permission from American Psychological Association. 
NOT THE PUBLISHED VERSION; this is the author's final, peer-reviewed manuscript. The published version may be accessed by following the link in the citation at the bottom of the page.

\section{Notes}

- Correspondence concerning this article should be addressed to Shane J. Lopez, Department of Psychology, JR Pearson, Lawrence, Kansas 66045. E-mail: sjlopez@ku.edu

\section{References}

APA Office of Ethnic Minority Affairs. (1993). Guidelines for providers of psychological services to ethnic, linguistic, and culturally diverse populations. American Psychologist, 48, 45-48.

Ben-Porath, Y. S. (1990). Cross-cultural assessment of personality: The case for replicatory factor analysis. In J. N. Butcher \& C. D. Spielberger (Eds.), Advances in personality assessment. (Vol. 8, pp. 27-48). Hillsdale, NJ: Erlbaum.

Cardemil, E. V., Reivich, K. J., \& Seligman, M. E. P. (2002). The prevention of depressive symptoms in low-income minority middle-school students. Prevention \& Treatment, 5, Article 8. Available on the World Wide Web: http://journals.apa.org/prevention/volume5/pre0050008a.html

Casas, J. M., \& Pytluk, S. D. (1995). Hispanic identity development: Implications for research and practice. In J. G. Ponterotto, J. M. Casas, L. A. Suzuki, \& C. M. Alexander (Eds.), Handbook of multicultural counseling (pp. 155-180). Thousand Oaks, CA: Sage.

Council of National Psychological Associations for the Advancement of Ethnic Minority Interests. (2000). Guidelines for research in ethnic minority communities. Retrieved November 5, 2001, from the American Psychological Association, Office of Ethnic Minority Affairs, Web site: http://www.apa.org/pi/oema/onlinebr.html

Department of Health and Human Services. (2001). Surgeon General's report on mental health: Culture, race, \& ethnicity: A supplement to mental health: A report of the Surgeon General. Washington, DC: DHHS. Retrieved November 11, 2001 from www.surgeongeneral.gov/library/mentalhealth/cre/

Duran, R. P. (1989). Testing of linguistic minorities. In R. L. Linn (Ed.), Educational Measurement (pp. 573-587). New York: American Council on Education.

Geisinger, K. F. (1994). Cross-cultural normative assessment: Translation and adaptation issues influencing the normative interpretation of assessment instruments. Psychological Assessment, 6, 304-312.

Knight, G. P., \& Hill, N. E. (1998). Measurement equivalence in research involving minority adolescents. In V. C. McLoyd and L Steinberg (Eds.) Studying minority adolescents: Conceptual, methodological, and theoretical issues (pp. 183-210). Mahwah, NJ: Erlbaum.

Lerner, R. (1995). America's youth in crisis: Challenges and options for programs and policies. Thousand Oaks, CA: Sage.

Prevention and Treatment, Vol. 5, No. 1 (May 2002). DOI. This article is (C) American Psychological Association and permission has been granted for this version to appear in e-Publications@ Marquette. American Psychological Association does not grant permission for this article to be further copied/distributed or hosted elsewhere without the express permission from American Psychological Association. 
NOT THE PUBLISHED VERSION; this is the author's final, peer-reviewed manuscript. The published version may be accessed by following the link in the citation at the bottom of the page.

Okazaki, S., \& Sue, S. (1995). Methodological issues in assessment research with ethnic minorities. Psychological Assessment, 7, 367-375.

Ponterotto, J. G. (1988). Racial/ethnic minority research in the Journal of Counseling Psychology: A content analysis and methodological critique. Journal of Counseling Psychology, 35, 410-418.

Prediger, D. J. (1994). Multicultural assessment standards: A compilation for counselors. Measurement and Evaluation in Counseling and Development, 27, 68-73.

Reiss, D., \& Price, R. H. (1996). National research agenda for prevention research: The National Institute of Mental Health Report. American Psychologist, 51, 1109-1115.

Roosa, M. W., Dumka, L. E., Gonzales, N. A., \& Knight, G. P. (2002). Cultural/ethnic issues and the prevention scientist in the $21_{\text {st }}$ century. Prevention \& Treatment, 5, Article 5. Available on the World Wide Web: http://journals.apa.org/prevention/volume5/pre0050005a.html

Sue, S. (1998). In search of cultural competence in psychotherapy and counseling. American Psychologist, 53, 440-448.

Vera, E. M., \& Reese, L. E. (2000). Preventive interventions with school-age youth. In S. D. Brown \& R. W. Lent (Eds.), Handbook of Counseling Psychology. New York: Wiley.

Yu, D. L., \& Seligman, M. E. P. (2002). Preventing depressive symptoms in Chinese children. Prevention \& Treatment, 5, Article 9. Available on the World Wide Web: http://journals.apa.org/prevention/volume5/pre0050009a.html

Prevention and Treatment, Vol. 5, No. 1 (May 2002). DOI. This article is (c) American Psychological Association and permission has been granted for this version to appear in e-Publications@ Marquette. American Psychological Association does not grant permission for this article to be further copied/distributed or hosted elsewhere without the express permission from American Psychological Association. 
NOT THE PUBLISHED VERSION; this is the author's final, peer-reviewed manuscript. The published version may be accessed by following the link in the citation at the bottom of the page.

\section{Appendix}

\section{Table 1. A Rubric for Examining Cultural Appropriateness of Prevention Programming}

\begin{tabular}{|c|c|}
\hline $\begin{array}{l}\text { Understanding the Cultural Context of the Problem } \\
\text { A rich picture of the target community's cultural context is developed through } \\
\text { the researchers' direct contact with members of the community and the fostering } \\
\text { of trusting relationships among researchers and all community stakeholders. } \\
\text { The depth of this understanding of the community is demonstrated in the text of } \\
\text { the research plan and published manuscript. }\end{array}$ & 2 \\
\hline $\begin{array}{l}\text { A sketchy picture of the target community's cultural context is developed through } \\
\text { the researchers' review of the literature and limited contact with community } \\
\text { stakeholders. Stakeholders' commitment to the work of the prevention research } \\
\text { is not assured. Some detail about the cultural context of the problem and } \\
\text { intervention is shared in the research plan or published manuscript. }\end{array}$ & 1 \\
\hline Description of the cultural context of the community is quite limited. & 0 \\
\hline $\begin{array}{l}\text { Distinguishing Between Cultures and Between Cultural Variables } \\
\text { Important distinctions are made between specific cultural groups and variables. } \\
\text { Specifically, cultural heterogeneity, orthogonality of race/ethnicity and SES, and } \\
\text { levels of acculturation and enculturation are examined and discussed in the } \\
\text { context of a research plan and manuscript. }\end{array}$ & 2 \\
\hline $\begin{array}{l}\text { Some distinctions between culture and cultural variables are made and described } \\
\text { in the research plan and manuscript. Some care is given to specifying cultural } \\
\text { heterogeneity, orthogonality of race/ethnicity and SES, and levels of acculturation } \\
\text { and enculturation. }\end{array}$ & 1 \\
\hline The myth of sameness is perpetuated in research practice and scholarly publications. & 0 \\
\hline $\begin{array}{l}\text { Developing a Culturally Appropriate Delivery System } \\
\text { Researchers and service providers are aware of their values, assumptions, and } \\
\text { worldview and how these may influence development and delivery of services. } \\
\text { Researchers also are aware of the limitations of their program and their } \\
\text { evaluation procedures. Researchers continually generate and test hypothesis about the } \\
\text { program's effects on participants. An ongoing process of collaboration with community } \\
\text { stakeholders is maintained. }\end{array}$ & 2 \\
\hline $\begin{array}{l}\text { Researchers and service providers engage in self-assessment of values, assumptions, } \\
\text { and biases. They maintain collaborative relationships with community stakeholders } \\
\text { throughout program development and delivery. A few culturally appropriate changes } \\
\text { are made to the program. }\end{array}$ & 1 \\
\hline $\begin{array}{l}\text { Researchers and service providers do not consider the cultural variables when } \\
\text { modifying a program for a new application with a group that differs from the one that } \\
\text { served as the pilot or validation group for the program. }\end{array}$ & 0 \\
\hline
\end{tabular}

Prevention and Treatment, Vol. 5, No. 1 (May 2002). DOI. This article is (C) American Psychological Association and permission has been granted for this version to appear in e-Publications@ Marquette. American Psychological Association does not grant permission for this article to be further copied/distributed or hosted elsewhere without the express permission from American Psychological Association. 
NOT THE PUBLISHED VERSION; this is the author's final, peer-reviewed manuscript. The published version may be accessed by following the link in the citation at the bottom of the page.

Facilitating Culturally Sensitive Evaluation

Culturally appropriate measurement technique, measurement equivalence, and data analysis procedures necessary for detecting mediating and moderating processes specific to and universal across cultural groups are used by researchers. (Appropriateness of measurement techniques and measurement equivalence are considered prior to program evaluation [via literature review and pilot testing] and subsequent to formal data collection [via analyses of measures in a cultural context].)

Cultural influences on measurement and data analyses are considered during research planning and program evaluation and some attempts are made to insure measurement equivalence.

However, culturally appropriate evaluation is not adequately achieved.

Cultural influences on measurement are addressed in the discussion section of the article or not at all.

Disseminating Prevention Research Findings to All Stakeholders

Findings are shared with community stakeholders via formal and informal channels and the "fit" of and rationale for these findings (as viewed by research participants and other community members) are shared in the scholarly papers describing the research,

Findings are shared with community stakeholders and feedback is garnered but this information is not incorporated (or only on a cursory level) into the discussion of the findings.

Little attempt is made to share information with community stakeholders.

Note. The table presents the criteria associated with culturally appropriate prevention science. The proper rating $(2,1,0)$ should be chosen to communicate the extent to which the examined work meets the criteria.

Prevention and Treatment, Vol. 5, No. 1 (May 2002). DOI. This article is (c) American Psychological Association and permission has been granted for this version to appear in e-Publications@ Marquette. American Psychological Association does not grant permission for this article to be further copied/distributed or hosted elsewhere without the express permission from American Psychological Association. 